\title{
Bankacılık Sektöründe Kredi Riskinin Temel Belirleyicilerine Yönelik Ampirik Bir Çalışma
}

\section{An Empirical Study on the Key Determinants of Credit Risk in the Banking Sector}

\section{Harun ÇETINKAYA ${ }^{1}$ [}

\section{öz}

Bu çalışmanın amacı, Türkiye'deki bankacılık sektörünün takipteki kredi oranlarında etkili olan faktörleri tespit etmektir. Bu amaçla çalışmada Türkiye'de faaliyet gösteren bankaların üç aylık finansal verileri kullanılmıştır. Analiz kapsamına 2014-2017 yılları arasında faaliyet gösteren en büyük hacme sahip ilk üç banka dâhil edilmiştir. Analiz panel veri regresyon yöntemi ile yapıımıştır. Çalışmanın sonuçları, bankaya özgü değişkenler arasında yer alan aktif karlılığı, banka büyüklüğü, net faiz marjı, finansman açığı ve özsermaye karlılığı değişkenlerinin \%99 güven düzeyinde ve istatistiksel olarak anlamlı olduğunu ortaya koymaktadır. Makroekonomik değişkenler arasında yer alan gayri safi yurtiçi hâsıla oranı değişkeni ve sermaye yeterlilik oranı değişkeni ile kredi riski arasında \%90 güven düzeyinde istatistiksel olarak anlamlı bir ilişki çıkmıştır. Bu sonuçlar bankacılık sektöründe takipteki kredileri dolayısıyla kredi riskini yönetmede hangi değişkenlerin ön plana alınması gerektiğini göstermesi bakımından önemli ve özgündür.

Anahtar kelimeler: Takipteki Krediler, Bankacılık Sektörü, Panel Veri Analizi

Jel Code: E43, G21, G11

\section{ABSTRACT}

The purpose of this study, the banking sector in Turkey is to identify the factors that influence their lending rates followed. The purpose of this study is to detect the factors that influence the rate of NPLs in the banking sector in Turkey. Quarterly financial data of banks operating in Turkey was used for this purpose. Quarterly financial data of banks operating in Turkey was used for this purpose. The first three banks with the largest volume operating between 2014-2017 were included in the analysis. The analysis was performed by method of panel data regression. The analysis was performed by method of panel data regression. The results of the study show that the variables such as asset profitability, bank size, net interest margin, finance deficit and return on equity among bank specific variables were statistically significant to a $99 \%$ confidence level.
'Doktora Öğrencisi, İstanbul Üniversitesi, İktisat Fakültesi, İktisat Bölümü, İstanbul, Türkiye

ORCID: H.Ç. 0000-0001-8708-1840

\section{Sorumlu yazar/Corresponding author: Harun ÇETINKAYA, \\ İstanbul Üniversitesi, Íktisat Fakültesi, İktisat Bölümü, İstanbul, Türkiye \\ E-posta/E-mail: harunctnkaya@gmail.com}

Başvuru/Submitted: 12.06 .2019

Kabul/Accepted: 03.07.2019

Atıf/Citation: Cetinkaya, H. (2019). Bankacılık sektöründe kredi riskinin temel belirleyicilerine yönelik ampirik bir çalışma. İktisat Politikası Araştırmaları Dergisi - Journal of Economic Policy Researches, 6(2), 121-134.

https://doi.org/10.26650/JEPR599442 
The results of the study show that the variables such as asset profitability, bank size, net interest margin, finance deficit and return on equity among bank specific variables were statistically significant to a $99 \%$ confidence level. There was a statistically significant relationship between the gross domestic product ratio which is macroeconomic variable and capital adequacy ratio variable and the credit risk at the $90 \%$ confidence level. These results are important and specific in terms of showing which variables should be taken into the foreground in managing non-performing loans in the banking sector, namely credit risk.

Keywords: Non-Performing Loans, Banking Sector, Panel Data Analysis

Jel Code: E43, G21, G11

\section{EXTENDED ABSTRACT}

The volume of loans or funds plays an important role in the growth and expansion of the impact areas of countries. The economic growth of a country is influenced by the institutions and organizations operating in the country. Banks fulfill the funding needs of firms and individual customers by providing loans. Banks may have problems in the collection of loans due to a number of negativity. These negativities that occur in the form of not paying the loans on time and in full cause the risk in the collection of the receivables. The failure of the borrower or counterparty to fully fulfill its obligations is defined as the credit risk faced by banks. The financial crises have shown that the increase in the non-performing loan ratios of the banks has indicated some problems in the real economy. For all these reasons, it is generally accepted that non-performing loans are a leading indicator that should be monitored and managed very carefully.

While non-performing loans shed light on the current situation of the banking sector, it also holds an important projection to understand the course of the general economy. The share of non-performing loans in total loans depicts the asset quality of banks, while the debt solvency of the household and the real sector is shown. In this respect, non-performing loans are a leading indicator in determining the banking performance as a micro indicator and as a macro indicator in the performance of the general economy. It is important to make accurate forecasts in order for economic policy recommendations to be made accurately and for banks to continue their operations healthily. It is important to make accurate forecasts in order for economic policy recommendations to be made accurately and for banks to continue their operations healthily. Therefore, in our study, non-performing loans were used as dependent variables in order to represent credit risk. Factors affecting NPLs in the banking sector in Turkey is aimed to identify what is going on. Thus, this study has investigated what happened the factors affecting the NPLs in the banking sector in Turkey. From this point of view, it is aimed to contribute to the literature. Working in conventional banks operating in the banking sector in Turkey using quarterly data in credit risk between the years 2014-2017 aimed to identify factors that are effective. For this purpose, the first three largest banks 
were included in the sample. Thus, the study was estimated by panel data regression method. The econometric model for the banking sector was found to be significant at $99 \%$ confidence level. The results of the study revealed that the selected variables were $67 \%$ effective in explaining the credit risk in the banking sector. While all the bank-specific variables selected in the research model were significant, only gross domestic product was significant among the macroeconomic variables.

The results show that a unit increase in the return on assets of the first three banks operating in the banking sector will result in an increase of 5.84 in credit risk. This result reveals that the increase in asset profitability will adversely affect credit risk. In addition, the results of the study show that a one-unit increase in the size of the bank will increase the non-performing loans, namely the credit risk by $1.30 \%$. The net interest margin variable in the model was positive and statistically significant at $99 \%$ confidence level. This result shows that a one-unit increase in the net interest margin will increase the credit risk by 0.03 . A one-unit increase in the share of liquid assets in total assets reduces the credit risk by 0.09 . A one-unit increase in the return on equity reduces the credit risk by 0.57 . This result supports the idea that the increase in shareholders' equity will decrease the credit risk. This result supports the idea that the increase in banks shareholders' equity reduces credit risk. The findings suggest that a one-unit increase in banks' capital adequacy ratios will reduce credit risk by 0.06 percent. Thus, the higher the capital adequacy ratio of the banks, the lower the exposure to credit risk. The results of the research show that there is a positive and statistically significant relationship between the gross domestic product variable and credit risk at $90 \%$ confidence level. In addition, the results showed that the inflation rate variable was meaningless in explaining the credit risk in banking.

The fact that banks have a solid liquidity structure is not only important in terms of the performance of the banks and the stability of the financial system, but also in terms of avoiding crises due to the increase in non-performing loans in the economy. Both the local banking crisis of 2000-2001 and the global financial crisis of 2007-2008 showed that nonperforming loans, ie, not managing credit risk effectively, could result in bankruptcy of banks. The study credits the banks operating in Turkey reveals factors that need attention in order to prevent exposure to risk. In this regard, considering the factors mentioned above, it is thought that banks that follow an appropriate policy will not have credit problems and keep their performance in good condition. 


\section{Kavramsal Çerçeve ve Teori}

Kredi ya da fon hacmi ülkelerin gelişmesi ve etki alanlarını genişletmesinde önemli bir fonksiyona sahiptir. Bir ülkenin ekonomik büyümesinde ülke içinde faaliyet gösteren kurum ve kuruluşların etkisi büyüktür. Bankalar fïmaların ve bireysel müşterilerin fon ihtiyaçlarını kredi vermek suretiyle gerçekleştirirler. Bankaların verdikleri kredilerin tahsilinde bir takım olumsuzluklar sebebiyle sorun yaşanabilir. Kredilerin zamanında ve tam olarak ödenmemesi şeklinde cereyan eden bu olumsuzluklar alacağın tahsilinde riskin doğmasına sebep olur. Kredi borçlusu ya da finansal sözleşmenin karşı tarafının yükümlülüklerini tam olarak yerine getirememesi bankaların karşılaştığı kredi riski olarak tanımlanmaktadır.

Bankalar ve çeşitli kredi kuruluşları tasarruf açığı bulunan kişilere belli bir maliyetle kredi vermek suretiyle reel sektörü sübvanse ederler. Söz konusu krediler eğer vadesinden önce ödenmezse sorunlu krediler durumuna düşer. Buradaki vade ise 90 gün şeklinde olup bu müddeti aşan krediler takipteki krediler şeklinde isimlendirilir (BDDK, 1.11.2006).

Bankalar verdikleri kredilerin sorunlu kredilere dönüşmemesi için karşı tarafın bankaya başvurmasından yükümlülüğünü yerine getirememesine kadar geçen süre içinde kredi takibi yaparlar. Kredi riski yönetimi de bu sürecin doğru planlanarak icra edilmesi, finansal hareketliliğin değerlendirilmesi ve alınması gerekli tedbirlerin zamanında uygulanması hususlarına ilişkin faaliyetlerin tümünü ifade etmektedir. Kredi riski verilen her kredi de ortaya çıkmakla beraber buradaki esas amaç risklerin yok edilmesi değil azaltılması şeklindedir. İyi bir kredi riski yönetimine sahip banka ise kredi verilmesinden başlayarak gerekli takipleri yapıp uygun pozisyonu alarak bu riski en aza indirebilen bankalardır (Sarı, 2004, s. 62). Bu bağlamda kredi riski yönetimi bankaların karlılığg ve sürdürülebilirliği için oldukça önemlidir.

Bankaların kredi riski yönetiminin iyi olması kapsamlı bir risk yönetim kültürüne sahip olunmasıyla mümkün olur. Kredi riski yönetim felsefesi sürekli riskten uzak durma amacına dayanmazken, söz konusu riskin ölçülebilir olması daha önemlidir. İyi bir kredi riski yönetimi anlayışının temeli piyasada meydana gelen rekabete uygun güce sahip olma ve kredilerin takibe düşme oranlarını aşağıya çekerek eldeki imkanlarla optimum getiri elde etme hedeflerine dayanır (Göğebakan \& Arda, 2004).

Bankalarda kredi riskini etkileyen temel belirleyicilerinden birisi takibe düşmüş kredi miktarını gösteren kalemleridir. Ekonomik durumda meydana gelen sıkılaşma zamanlarında artan işsizlik ve gelecek endişesi sebebiyle ve ekonominin içinde yer alan işletmelerin de kazandıklarından daha azını kazanma endişesinin artmasından dolayı ödemesi geciken kredilerde yukarı yönlü hareketler görülmektedir. 
Yaşanan finansal krizler göstermiştir ki bankaların takipteki kredi oranlarının artması reel ekonomide bir takım sorunların varlığına işaret etmiştir. Bu tür artışların olduğu dönemlerde hükümetler bankalara bu açıkları kapatmak için kaynak sağlamak durumunda kalırlar. Bu hamle cari işlemler dengesinde bir sorun yaratsa da arz durumunun artmasını sağlar. Tüm bu sebeplerden dolayı takipteki kredilerin oldukça dikkatli takip edilmesi ve yönetilmesi gereken öncü bir gösterge olduğu genel kabul görmektedir (Claessens, Klingebiel, \& Laeven, 2001).

Takipteki krediler bankacılık sektörünün mevcut durumuna 1şık tutan bir gösterge iken genel ekonominin gidişatını anlamaya yönelik de önemli bir projeksiyon tutar. Takipteki kredilerin toplam krediler içindeki payı bankaların aktif kalitesini resmederken hane halkının ve reel sektörün de borç ödeme gücünü göstermektedir (Sözer, 2010, s. 29). Bu açından takipteki krediler diğer adıyla tahsili gecikmiş krediler mikro bazda bankacılığın makro bazda ise genel ekonominin performansının tespitinde öncü bir gösterge niteliğindedir. İktisadi politika önerilerinin doğru yapılması ve bankaların faaliyetlerini sağlıklı bir şekilde sürdürebilmeleri için tahminlerin doğru yapılması önem arzetmektedir. Buradan hareketle çalışmamızda kredi riskini temsilen takipteki krediler bağımlı değişken olarak kullanılmıştır. Türkiye'deki bankacılık sektöründe takipteki kredileri etkileyen faktörlerin neler olduğu tespit edilerek literatüre katkı sağlamak amaçlanmıştır.

\section{Literatür Değerlendirmesi}

Kredi riskinin temel belirleyicilerini tespit etmeye yönelik literatürde birçok çalışmaya rastlanmaktadır. Bu çalışmalardan belli başlıcaları aşağıda özetlenmiştir.

Ahmad ve Ahmed (2004), kredi riski üzerinde etkisi olan faktörler konusunda Malezya'daki İslami ve geleneksel bankalara yönelik 1996-2002 döneminde karşılaştırmalı bir çalışma yapmışlardır. Bulgular yönetim etkinliğinin, risk ağırlıklı varlıkların ve toplam aktiflerin büyüklüğünün İslami bankacılığın kredi riski üzerinde önemli bir etkiye sahip olduğunu göstermektedir. Konvansiyonel bankalarda kredi riski üzerinde krediler, sermaye düzenlemeleri, kredi karşılıkları ve risk ağırlıkları varlıkların yüksek derecede ilişkili olduğu sonucuna ulaşılmıştır. Çalışmanın bulgularına göre, riskli varlıkların yönetimindeki verimlilik, kredi riskini azaltmak için çok önemlidir.

Ghost ve Das 2007 yılında yaptıkları çalışma ile Hindistan devlet bankalarının 19942005 dönemindeki sorunlu kredileri üzerinde etkisi olan mikroekonomik ve makroekonomik faktörleri incelemişlerdir. Panel veri analizi yardımıyla yapılan çalışmanın sonuçları kredi riski üzerinde makro seviyede gayri safi yurt içi hasıla büyüme oranı değişkeninin etkili olduğuna ulaşmıştır. Ayrıca banka seviyesinde reel kredi büyümesinin, gider kalemlerinin ve banka büyüklüğünün sorunlu kredileri etkilemede etkili olduğu çalışmanın bir diğer bulgusu arasında yer alır. 
Suresh ve diğerleri tarafından 2009 yılında Hindistan'daki 15 özel bankada kredi riskini ölçmek ve yönetmek amacıyla bir çalışma yapılmıştır. Çalışma çeşitlendirilmiş kredi avansları portföyünün ve özel bankaların NPA'larının ilişkisini analiz etmek için yapılmıştır. Çalışma sonuçlarında tüm özel sektör bankalarının takipteki varlıkları (NPA) ile bireysel bankacılık arasında ilişki bulunamamış ve iş portföylerinin takipteki varlıklara katkısının önemli rolü olduğuna ulaşılmıştır. Regresyon ve korelasyon analizi ve anova testi ile yapılan çalışma bireysel krediler ile takipteki varlıkların (NPA) ters orantılı olduğunu tüm bölgelerde ortaya koymuştur. Sonuçlar bankaların daha iyi bir kredi riski yönetim sistemini kurmak ve yönetmek için portföylerini çeşitlendirmeleri gerektiğini tavsiye etmektedir.

Espinoza ve Prasad, 2010 yılında Körfez ülkelerindeki bankacılık sektöründeki takipteki kredilerin üzerinde etkili olan belirleyicileri tespit etmeye yönelik bir çalışma yapmışlardır. Çalışmanın örneklemini körfez ülkelerindeki seksen bankadan elde edilen veriler oluşturmaktadır. Panel veri analizi ile yapılan çalışmanın sonuçları hem makro faktörlerin hem de bankaya özgü özelliklerin uygun olmayan kredilerin seviyesini belirlediğini ortaya koymaktadır. Çalışma ayrıca, küresel finansal piyasa koşullarının bankaların takipteki alacakları üzerinde etkili olduğunu göstermiştir. Ayrıca bankalar için kurulan kontrol faktörleri arasında verimlilik ve banka bilançolarındaki genişleme önemli bulunmuştur.

Cristea ve diğerleri (2010), Türkiye'de faaliyet gösteren yerli ve yabancı bankaların 2006 yılı finansal rasyolarından hareketle başarı durumlarının analizini yapmışlardır. Doğrusal regresyon ve diskiriminant analizi yöntemlerine göre yapılan çalışmada 17 yerli ve 8 yabancı mevduat bankası baz alınmıştır. Bankaların performans analizleri TCMB'dan alınan aktif karlılığı, sermaye yeterlilik rasyosu, karlılık, kar zarar yapısı, likidite durumu, sektör payı ve faaliyet oranları gibi rasyolar yardımıyla yapılmıştır. Çalışma sonuçlarında Türkiye' deki yerli mevduat bankalarının yabancı mevduat bankalarından daha başarılı olduğu ifade edilmiştir. Bu sonuç yabancı bankaların Türkiye'deki şube sayılarının az olmasından kaynaklandığının belirtildiği çalışmada bankacılık sistemindeki yüksek rekabet dolayısıyla banka karlılıklarının kredi kartı ve komisyon ücretlerinden geldiği vurgulanmıştır.

Koyunca ve Saka (2011), çalışmalarında sorunlu hale gelip takibe düşen kredilerin 1986'dan 2008 yılları arasında yatırımlara ve kamu ilişkisi bulunmayan sektöre verilen kredilere etkisini incelemişlerdir. Çalışmada analiz çoklu regresyon analizi yöntemine göre yapılmıştır. Sonuçlar çalışmanın bağımsız değişkeni olan takipteki krediler ile kamu iştiraki ya da kamuyla ilişkisi bulunmayan sektöre verilen krediler ve yatırımları ifade eden bağımlı değişkeni arasında \%99 güven düzeyinde negatif ve istatistiksel olarak 
anlamlı bir ilişkiyi göstermektedir. Bu sonuç takipteki kredi oranlarının artmasının özel sektöre verilen kredi düzeyini azaltacağı ve ekonomiyi olumsuz olarak etkileyeceğini ifade etmektedir.

Keklik (2011), yaptı̆̆ı çalışmasında Türkiye'deki bankacılık sektörünün kredi riski yönetim becerisini analiz etmiştir. Çalışmada veri zarflama analizi yöntemi yardımıyla Türkiye'deki bankaların aktif gücünü belli rasyolarla ölçerek banka performans analizi yapılmıştır. Yapılan analiz sonrasında total varlıkların ve total mevduatın toplam kredilerden daha iyi performans gösterdiği tespit edilmiştir. Araştırma bankacılık sektörü için sorunlu rasyoları tespit edip önlem almak açısından dikkate değerdir.

Klein tarafından 2013 yılında yapılan bir çalışmada Orta Doğu ve Güney Doğu Avrupa'daki (CESEE) tahsili gecikmiş kredileri incelemektedir. 1998-2011 dönemini inceleyen çalışma takipteki kredilerin hem makroekonomik koşullara hem de bankaya özel faktörlerle ilişkili olduğunu tespit etmiştir. Çalışmada makroekonomik değişken olarak kullanılan GSYİH büyümesi, işsizlik oranı, enflasyon oranı gibi değişkenler ile tahsili gecikmiş krediler arasında istatistiksel olarak anlamlı bir korelasyon keşfedilmiştir. Çalışma aynı zamanda bankacılık sektörünün reel sektöre etkisinin kuvvetli olduğu sonucuna ulaşırken; öz sermaye karlılığı bağımsız değişkeniyle tahsili gecikmiş krediler arasında negatif ve istatistiksel olarak anlamlı bir korelasyon elde edilmiştir.

Küresel finansal kriz döneminde İslami bankalar ile geleneksel bankaların kredi riski ve verimlilik seviyesini araştıran Fehri ve Chkoundali (2015), geleneksel bankaların çoğunun İslami olanlardan daha yüksek kredi riskine sahip olduğu sonucuna ulaşmışlardır. Örneklemi 28 ülkedeki toplam 99 İslami ve 110 geleneksel bankadan oluşan araştırmanın sonuçlarına göre, risk ile finansal krizler arasında yüksek korelasyon bulunurken, verimsizlik derecesinin her iki banka türünde de benzer olduğuna ulaşılmıştır. Nurul ve diğerleri (2015) ise 13 ülkede toplam 156 geleneksel ve 37 İslam bankasının verilerinden hareketle kredi riski yönetimlerini karşılaştırmıştır. Yazarlar, kredi riskinin ölçülmesinde kullanılan tekniklerin, hangi bankacılık sisteminin daha yüksek kredi riskine maruz kaldığının tespit edilmesinde önemli rol oynadığını vurgulamışlardır.

Özkan ve Iş1l (2016) tarafından Türkiye'de faaliyet gösteren dört katılım bankasının 2006-2014 yılları arası üç aylık verileri kullanılarak kredi risklerini belirleyen faktörler araştırılmıştır. Çalışma ile kredilerin toplam varlıklar içindeki payının arttıkça ya da katılım bankalarının varlık büyüklüğünün arttıkça kredi risklerinin azalacağı sonucuna ulaşılmıştır. Çalışmada ayrıca katılım bankalarında kredi riskinin artmasının bulguları olarak geri ödenmeme riski taşıyan kredilere karşı ayrılan özel karşılıkların toplam varlıklar içindeki payının artması gösterilmiştir. 


\section{Metodoloji}

\section{1. Örneklem ve Veri Seti}

Araştırmamızın örneklemini Türkiye'de faaliyet gösteren en büyük banka hacmine sahip ilk üç banka oluştururken, veri seti 2014-2017 yılları arasındaki üç aylık finansal tablo verilerinden hesaplanarak oluşturulmuştur. Makroekonomik değişkenlerden GSYH verisi FRED Graph Observations'dan alınmıştır. Enflasyon verisi ise OECD'den elde edilmiştir. Araştırma kapsamındaki bankalar Ziraat Bankası, İş Bankası ve Garanti Bankası'dır. Veriler TCMB, TBB ve bankaların internet sitelerinden elde edilmiştir. Çalışmada yer alan tüm değişkenlere ilişkin bilgiler Tablo 1'de yer almaktadır.

Tablo 1. Model Değişkenleri ve Tanımları

\begin{tabular}{|c|c|c|c|}
\hline \multicolumn{4}{|c|}{ Bağımlı Değişken } \\
\hline $\mathbf{Y}$ & NPL & Takipteki Krediler & Takipteki Krediler/Toplam Krediler \\
\hline \multicolumn{4}{|c|}{ Bankaya Özgü } \\
\hline \multicolumn{4}{|c|}{ Bağımsız Değişkenler } \\
\hline $\mathbf{X 1}$ & CAR & Sermaye Yeterlilik Oranı & Sermaye Yeterliliği Standart Oranı \\
\hline $\mathbf{X} 2$ & ROA & Aktif Karlılığ & Vergi Sonrası Net Kar / Toplam Varlıklar \\
\hline $\mathbf{X 3}$ & Size & Banka Büyüklüğü & Toplam Varlıkların Doğal Logaritması \\
\hline X4 & NIM & Net Faiz Marj1 & Net Faiz Geliri / Toplam Varlıklar \\
\hline X5 & LR & Likidite Riski & Finansman Açığ / Toplam Varlıklar \\
\hline X6 & ROE & Özsermaye Karlılığ & Vergi Sonrası Net Kar / Toplam Özsermaye \\
\hline \multirow{2}{*}{\multicolumn{4}{|c|}{$\begin{array}{c}\text { Makroekonomik } \\
\text { Bağımsız Değişkenler }\end{array}$}} \\
\hline & & & \\
\hline $\mathbf{X} 7$ & GDP & Gayri Safi Yurtiçi Hâsıla & Gayri Safi Yurtiçi Hâsıla Çeyreklik Büyüme Oranı \\
\hline X8 & INF & Enflasyon & Enflasyon Çeyreklik Oranı (TÜFE) \\
\hline
\end{tabular}

\subsection{Araştırma Modeli ve Analiz}

Araştırmada, Türkiye'de faaliyet gösteren bankaların kredi riskinin temel belirleyicilerini tespit etmek için panel veri regresyon tekniği kullanılmıştır. Panel verileri, belirli bir zaman dilimi boyunca kesitlerdeki örnek gözlemleri toplayan bir tekniktir. Panel verisinde gözlemler N x T boyutu ile endekslenir. N, bankaların (panellerin) sayısıdır ve T, yıllık, aylık veya günlük gibi bir zaman dizisinin boyutudur. Yatay kesit ve zaman serisi analizlerinde $\mathrm{N}$ $\mathrm{x} \mathrm{T}$ boyutlu analizler yapılamaz. Panel veri ise çoklu doğrusal bağlantı sorununu en aza indirerek bu analizleri tek başına yapabilir ve bu sebeple tercih edilmiştir (Baltagi, 2005).

$$
\mathrm{Y}_{\mathrm{it}}=\beta_{0}+\beta_{1} \mathrm{X} 1_{\text {it }}+\beta_{2} \mathrm{X} 2_{\mathrm{it}}+\beta_{3} \mathrm{X} 3_{\mathrm{it}}+\beta_{4} \mathrm{X} 4_{\mathrm{it}}+\beta_{5} \mathrm{X} 5_{\mathrm{it}}+\beta_{6} \mathrm{X} 6_{\mathrm{it}}+\beta_{7} \mathrm{X} 7_{\mathrm{it}}+\beta_{8} \mathrm{X} 8_{\mathrm{it}}+\mathrm{U}_{\mathrm{it}}
$$

Tablo 1'de gösterilen değişkenlerin yer aldığı araştırmamızın ekonometrik modeli yukarıdaki şekildedir. Burada ' $i$ ' ifadesi yatay kesitleri, ' $t$ ' ise zaman boyutunu ifade eden alt 
indisleri temsil etmektedir. Modelde yer alan $\beta_{1}$ 'den $\beta_{6}$ 'ya kadar olan katsayılar bankaya özgü bağımsız değişkenlere ait eğim katsayılarını ve $\beta_{7}$ ve $\beta_{8}$ katsayıları ise makroekonomik değişkenlere ait eğim katsayılarını ifade etmektedir. $\beta_{0}$ sabit kesişim katsayısını ve $U_{\text {it }}$ ise hata terimini göstermektedir

\section{Ampirik Bulgular}

Çalışma panel veri regresyon analizi yardımıyla yapılmış ve Türkiye'de faaliyet gösteren bankaların takipteki kredilerini dolayısıyla kredi riskini etkileyen temel belirleyiciler tespit edilmeye çalışılmıştır. Aşağıdaki tabloda değişkenlere ilişkin ortalama, standart sapma, minimum ve maksimum değerleri yer almaktadır.

Tablo 2. Özet İstatistikler

\begin{tabular}{ccccc}
\hline Tanımlayıcı İstatistikler & \multicolumn{5}{c}{ Minimum } & Maksimum \\
\hline Değişken & Ortalama & Standart Sapma & 0.0158 & 0.2529 \\
NPL & 0.0272 & 0.0337 & 0.1228 & 0.1793 \\
CAR & 0.1475 & 0.0120 & 0.0022 & 0.006 \\
ROA & 0.0040 & 0.0008 & 0.1923 & 0.1994 \\
Size & 0.1955 & 0.0019 & 0.0076 & 0.1044 \\
NIM & 0.0114 & 0.0137 & -0.0906 & 0.1371 \\
LR & 0.0591 & 0.0574 & 0.023 & 0.057 \\
ROE & 0.0380 & 0.0078 & 1.9355 & 2.5068 \\
INF & 2.1676 & 0.1646 & -0.9178 & 1.7007 \\
GDP & 0.5050 & 0.5629 & &
\end{tabular}

Yukarıdaki tablodaki sonuçlar incelendiğinde kredi riskini temsil eden takipteki krediler değişkenine ait ortalamanın \%2,7 olduğu görülmektedir. Bu sonuç bankaların takipteki kredilerinin toplam krediler içindeki payını gösterirken, her 100 krediden 2,7'sinin geri ödenmesinde sorun yaşadığını göstermektedir. Sermaye yeterlilik oranı (CAR) değişkenine ait ortalama \%14 civarındadır. Bu sonuç Türkiye'deki bankacılık sektörünün sermaye rasyolarının uluslararası Basel bankacılık kriterlerinin (\%8) oldukça üstünde seyrettiğini ortaya koymaktadır. Gayri safi yurt içi hâsıla (GDP) çeyreklik büyüme oranı değerine ait örneklem dönemindeki ortalama değer $\% 5,05$ 'dir. Bu sonuç incelenen dönemde Türkiye'deki üç aylık ortalama büyüme oranını göstermektedir.

Yukarıdaki ön analiz değerlerinden sonra panel veri için ilk olarak birim etki ve zaman etki sınaması yapılmıştır. Örneklemde yer alan bankalarda zaman etkisinin testi için F testi, Breusch-Pagan LM testi, En Çok Olabilirlik testi ve Score testi yapılarak zaman etkisinin olmadığı sonucuna ulaşılmıştır. Birim etki için aynı testler yapılıp birim etkinin olduğu sonucuna ulaşı1mıştır. Sonuçlar Tablo 3’te gösterilmiştir. 
Tablo 3. Zaman ve Birim Etkinin Testi

\begin{tabular}{ccccc}
\hline & F Testi & $\begin{array}{c}\text { Breusch-Pagan } \\
\text { LM Testi }\end{array}$ & $\begin{array}{c}\text { Olabilirlik Oranı } \\
\text { (LR) Testi }\end{array}$ & Score Testi \\
\hline Zaman Etki Sinamas1 (Prob.) & 0.99 & 1.00 & 1.00 & 1.00 \\
Birim Etki Sinamas1 (Prob.) & 0.00 & 1.00 & 0.00 & 0.00 \\
\hline
\end{tabular}

Tablo 3'ten görüldüğü gibi zaman etkisi için yapılan test sonuçlarından hareketle zaman etkilerinin standart hatalarının sıfıra eşit olduğu şeklinde kurulan $\mathrm{H}_{0}$ hipotezi kabul edilip zaman etkilerin etkin olmadığı görülmüştür. Birim etki için yapılan testler sonucunda birim etkilerin sıfıra eşit olduğunu iddia eden $\mathrm{H}_{0}$ hipotezini reddedilerek birim etkilerin etkin olduğu sonucuna ulaşılmıştır.

Analizin devamında birim etkinin varlığı altında en uygun tahminci seçimi için Hausman testi yapılarak sonuçlar Tablo 4’te gösterilmiştir.

Tablo 4. Hausman Testi Sonuçları

\begin{tabular}{|c|c|c|}
\hline \multirow{2}{*}{ Değişkenler } & \multicolumn{2}{|c|}{ Katsayı Değerleri } \\
\hline & Sabit Etkiler Modeli & Rassal Etkiler Modeli \\
\hline CAR & -0.0816 & -0.3810 \\
\hline ROA & 5.8443 & 25.931 \\
\hline Size & 1.3003 & -0.7464 \\
\hline NIM & 0.0337 & 0.0161 \\
\hline LR & -0.0982 & -0.0588 \\
\hline ROE & -0.5763 & -2.9891 \\
\hline INF & 0.0010 & 0.0126 \\
\hline GDP & 0.0004 & 0.0021 \\
\hline Ki-Kare: & \multirow{2}{*}{\multicolumn{2}{|c|}{$\begin{array}{c}28.91 \\
0.0000\end{array}$}} \\
\hline Prob. Değeri: & & \\
\hline Seçilen Model: Sabit Etkiler Modeli & & \\
\hline
\end{tabular}

Hausman testi sonucunda prob. değeri 0.05 değerinden küçük olduğundan $\mathrm{H}_{0}$ hipotezi reddedilerek sabit etkiler modelinin anlamlı olduğu sonucuna ulaşılmıştır. Bu sonuçtan hareketle örneklemdeki bankaların bağımsız değişkenlerinin bağımlı değişkene etkisi sabit etkiler testi sonuçları ile açıklanacaktır. Bu sonuçlar aşağıda Tablo 5 'te gösterilmiştir.

Analizin devaminda otokorelasyon, heteroskedasite ve birimler arası korelasyon ilişkilerinin varlığı için çeşitli testler yapılmıştır. Otokorelasyon testinin hipotezi modelde otokorelasyon yoktur şeklindedir. Durbin-Watson ve Baltaqi-Wu LBI test ortalamaları 2 değerinden küçük olduğundan $\mathrm{H}_{0}$ hipotezi reddedilmiş ve modelde otokorelasyonun olduğu görülmüştür. Modelde değişen varyansların durumu heteroskedasite ile test edilmiştir. Modified Wald testi sonuçlarına göre $\mathrm{H}_{0}$ hipotezi reddedilmiş ve hata terimlerinin aynı varyansa sahip olmadığı görülmüştür. Bu durumda alternatif hipotez $\mathrm{H}_{1}$ daha tutarlı olduğundan kabul edilmiş ve heteroskedasitenin olduğu sonucuna ulaşılmıştır. 
Modelde birimler arası korelasyonun varlığı Breusch Pagan Testi, Pesaran CD Testi, Frees Testi ve Friedman Testi aracılığı ile sınanmıştır. Breusch Pagan Testi sonucuna göre birimler arası korelasyon yoktur. Birimler arası ilişkisizliği test etmek için Pesaran testi yapılmıştır. Sonuçlara göre prob değeri 0,05 değerinden büyük olduğundan $\mathrm{H}_{0}$ hipotezi kabul edilmekte ve birimler arası korelasyonun olmadığı anlaşılmaktadır. Çalışmada birimler arası korelasyon sınayıcısı olan Friedman testi ile yatay kesit bağımsızlığının sınaması yapılmıştır. Sonuçlara göre $\mathrm{H}_{0}$ hipotezi kabul birimler arası korelasyon görülmüştür. Birimler arası korelasyon için yapılan son test olan Frees testi sonuçlarına göre \%95 güven düzeyinde test istatistik değeri kritik değerden küçük olduğundan $(0.058<0.243) \mathrm{H}_{0}$ hipotezi reddedilememekte ve birimler arası korelasyonun olmadığı anlaşılmaktadır. Sonuçlar çalışmada birimler arası korelasyon sorunun olmadığını ortaya koymuştur.

Türkiye'deki bankacılık sektöründe kredi riski üzerinde etkili olan temel faktörleri tespit etmek için en büyük üç bankanın verilerinden yararlanılmıştır. Analizde gerekli düzeltmelere uygun tahminci seçimi yapılarak regresyon analizi yapılmıştır. Modelde otokorelasyon ve heteroskedasitenin varlığından dolayı Driscoll-Kraay standart hatalar tahmincisi ile düzeltme yapılmıştır (Tatoğlu, 2013). Nihai analizle yapılan test sonuçları Tablo 5'te gösterilmiştir.

Tablo 5: Bankacılık Sektöründen Kredi Riskinin Temel Belirleyicileri

\begin{tabular}{|c|c|c|c|}
\hline NPL & Katsayılar & Drisc/Kraay Std. Hata & $\mathbf{P}>|\mathbf{t}|$ \\
\hline CAR & $-0.0816^{*}$ & 0.0402 & 0.064 \\
\hline ROA & $5.8443 * * *$ & 1.0338 & 0.000 \\
\hline Size & $1.3003^{* * *}$ & 0.2582 & 0.000 \\
\hline NIM & $0.0337 * * *$ & 0.0064 & 0.000 \\
\hline LR & $-0.0982 * * *$ & 0.0148 & 0.000 \\
\hline ROE & $-0.5763 * * *$ & 0.1081 & 0.000 \\
\hline INF & 0.0010 & 0.0014 & 0.495 \\
\hline GDP & $0.0004 *$ & 0.0002 & 0.064 \\
\hline Sabit & $-0.2188 * * *$ & 0.0456 & 0.000 \\
\hline \multicolumn{4}{|l|}{ Otokorelasyon: } \\
\hline Durbin-Watson Testi & 1.7064 & $\mathrm{~F}(2,28)=38.03$ & \\
\hline Baltagi-Wu LBI Testi & 1.8495 & Prob $=0.0000$ & \\
\hline \multicolumn{4}{|l|}{ Heteroskedasite: } \\
\hline Modified Wald Testi & 0.0022 & & \\
\hline \multicolumn{4}{|c|}{ Birimler Arası Korelasyon: } \\
\hline Breusch-Pagan Testi & 0.2565 & & \\
\hline Pesaran CD Testi & 0.5253 & & \\
\hline Friedman Testi & 0.0081 & & \\
\hline Frees Testi & 0.058 & $(0.058<0.2431 * *)$ & \\
\hline $\mathbf{R}^{2}$ & 0.6670 & & \\
\hline Prob. & $0.0000^{* * *}$ & & \\
\hline Gözlem Sayıs1 & 42 & & \\
\hline
\end{tabular}

Not: Sabit etkiler modeli yardımıyla panel veri analizi yapılmıştır. Anlamlılık düzeyleri ***\%1, ** \%5, * \%10 şeklindedir. 


$$
\begin{aligned}
& \mathrm{NPL}=-0,21-0,08 .(\mathrm{CAR})+5,84 .(\mathrm{ROA})+1,30 .(\mathrm{ISIZE})+0,03 .(\mathrm{NIM})-0,09 .(\mathrm{LR})- \\
& \text { 0,57. }(\mathrm{ROE})+0,0010 .(\mathrm{IINF})+0,0004 .(\mathrm{IGDP})
\end{aligned}
$$

Tablo 5'teki bulgular incelendiğinde, modelde yer alan 8 değişkenden 7'sinin anlamlı olduğu görülmektedir. Sonuçlar incelendiğinde modelde yer alan aktif karlılığı, banka büyüklüğü, likidite riski, net faiz marjı, özsermaye karlılığı ve sabit değişkenleri \%99 güven düzeyinde anlamlı olduğu görülmektedir. Sermaye yeterlilik oranı ve gayri safi yurtiçi hasıla değişkenleri ise \%90 güven düzeyinde istatistiksel olarak anlamlı çıkmıştır.

$\mathrm{R}^{2}$ değeri bağımsız değişkenlerin bağımlı değişkeni açıklama gücünü göstermektedir. Modelde seçtiğimiz bağımsız değişkenler takipteki krediler bağımlı değişkenini \%67 gibi bir oranında açıklayabilmektedir. Model, \%99 güven düzeyinde istatistiksel olarak anlamlıdır (Prob. $=0,00)$. Aktif karlılığg $($ ROA) değişkeni ile takipteki krediler arasındaki ilişki sonuçları \%99 güven düzeyinde pozitif yönde ve istatistiksel olarak anlamlı çıkmıştır. Bulgular aktif karlılığında meydana gelecek bir birimlik artışın takipteki kredilerde 5,84 oranında bir artışa sebep olacağını göstermektedir. Bu sonuç aktif karlılığındaki artışın kredi riskini olumsuz etkileyeceğini ortaya koymaktadır. Banka büyüklüğü (SIZE) değişkeni \%99 güven düzeyinde pozitif yönlü ve istatistiksel olarak anlamlı çıkmıştır. Banka büyüklügünde meydana gelecek bir birimlik artış takipteki kredileri dolayısıyla kredi riskini \%1,30 arttırmaktadır. Modelde yer alan net faiz marjı (NIM) değişkeni \%99 güven düzeyinde pozitif ve istatistiksel olarak anlamlı çıkmıştır. Bu sonuç net faiz gelirinde meydana gelecek bir birimlik bir artışın kredi riskini 0,03 oranında arttıracağını göstermektedir. Likit aktiflerin toplam varlıklar içindeki payı şeklinde tanımlanan likidite riski (LR) değişkeni \%99 güven düzeyinden negatif yönde ve istatistiksel olarak anlamlı çıkmıştır. Likidite riskinde meydana gelecek bir birimlik bir artış kredi riskini 0,09 oranında düşürmektedir.

Öz sermaye karlılığı (ROE) değişkeni \%99 güven düzeyinde negatif yönde ve istatistiksel olarak anlamlı çıkmıştır. Özsermaye karlılığında meydana gelecek bir birimlik artış kredi riskini 0,57 oranında düşürmektedir. Bu sonuç bankaların özsermaye miktarının artışının kredi riskini düşüreceği şeklindeki düşünceyi desteklemektedir. Modelde yer alan sermaye yeterlilik oranı (CAR) değişkeni \%90 güven düzeyinde negatif yönde ve istatistiksel olarak anlamlı bulunmuştur. Bu sonuç bankaların sermaye yeterlilik oranlarında meydana gelecek bir birimlik artışın kredi riskini 0,08 oranında düşüreceğini ifade etmektedir. Böylece bankaların sermaye yeterlilik oranları ne kadar yüksek seviyede olursa kredi riskine maruz kalma durumları da o kadar azalır şeklinde bir yorumda bulunabiliriz. Modeldeki makroekonomik değişkenlerden gayri safi yurtiçi hasıla (GDP) değişkeni \%90 güven düzeyinde pozitif ve istatistiksel olarak anlamlı çıkmıştır. Çalışmada makroekonomik değişkenler arasında yer alan enflasyon oranı (ENF) değişkenlerine ait prob. değeri pozitif ancak istatistiksel olarak anlamlı çıkmamıştır. Modelde yer alan sabit değişkene ilişkin 
katsayının negatif ve \%99 güven düzeyinde istatistiksel olarak anlamlı olduğu anlaşılmaktadır. Bu sonuç seçilen bağımsız değişkenler sıfır iken sabit terimdeki 1 birimlik artışın kredi riskini 0,21 oranında azaltacağı anlamına gelmektedir.

\section{Sonuç}

Çalışmada Türkiye'deki bankacılık sektöründe faaliyet gösteren geleneksel bankaların 2014-2017 yılları arasındaki çeyreklik verilerinden hareketle kredi riskinde etkisi olan faktörlerin tespit edilmesi amaçlanmıştır. Bu amaçla örneklem kapsamına en büyük ilk üç banka dahil edilmiştir. Buradan hareketle çalışma panel veri regresyon yöntemiyle tahmin edilmiştir. Çalışmada bankacılık sektörü için oluşturulan ekonometrik modeller \%99 güven düzeyinde anlamlı bulunmuştur. Çalışma sonuçları seçilen değişkenlerin bankacılık sektöründeki kredi riskini açıklamada $\% 67$ oranında etkili olduğunu ortaya koymuştur. Araştırma modelinde seçilen bankaya özgü değişkenlerin tümü anlamlı çıkarken makroekonomik değişkenlerden sadece gayri safi yurtiçi hasıla anlamlı çıkmıştır.

Sonuçlar bankacılık sektöründe faaliyet gösteren ilk üç bankanın aktif karlılığında meydana gelecek bir birimlik artışın kredi riskinde 5,84 oranında bir artışa sebep olacağını göstermektedir. Bu sonuç aktif karlılığındaki artışın kredi riskini olumsuz etkileyeceğini ortaya koymaktadır. Ayrıca çalışma sonuçları banka büyüklügünnde meydana gelecek bir birimlik artışın takipteki kredileri dolayısıyla kredi riskini \%1,30 arttıracağını göstermektedir. Modelde yer alan net faiz marjı (NIM) değişkeni \%99 güven düzeyinde pozitif ve istatistiksel olarak anlamlı çıkmıştır. Bu sonuç net faiz marjında meydana gelecek bir birimlik bir artışın kredi riskini 0,03 oranında arttıracağını göstermektedir. Likit aktiflerin toplam varlıklar içindeki payında meydana gelecek bir birimlik bir artış kredi riskini 0,09 oranında düşürmektedir. Özsermaye karlılığında meydana gelecek bir birimlik artış kredi riskini 0,57 oranında düşürmektedir. Bu sonuç bankaların özsermaye miktarının artışının kredi riskini düşüreceği şeklindeki düşünceyi desteklemektedir. Bulgular bankaların sermaye yeterlilik oranlarında meydana gelecek bir birimlik artışın kredi riskini 0,06 oranında düşüreceğini ifade etmektedir. Böylece bankaların sermaye yeterlilik oranları ne kadar yüksek seviyede olursa kredi riskine maruz kalma durumları da o kadar azalacağı ortaya çıkmaktadır. Araştırma sonuçları gayri safi yurtiçi hasıla (GDP) değişkeni ile kredi riski arasında \%90 güven düzeyinde pozitif ve istatistiksel olarak anlamlı bir ilişkinin olduğunu göstermektedir. Ayrıca sonuçlar enflasyon oranı (INF) değişkeninin bankacılıkta kredi riskini açıklamada anlamsız olduğunu göstermiştir.

Bankaların sağlam likidite yapısına sahip olması sadece bankaların performansı ve finansal sistemin istikrarı açısından değil aynı zamanda ekonomide takipteki kredilerin artışından kaynaklı krizlerin yaşanmaması açısından da büyük önem taşımaktadır. Hem 2000-2001 yerel bankacılık krizi hem de 2007-2008 küresel finans krizi takipteki kredilerin dolayısıyla kredi 
riskinin etkin bir şekilde yönetilmemesinin bankaların iflası ile sonuçlanabileceğini göstermiştir. Çalışma Türkiye'de faaliyet gösteren bankaların kredi riskinden dolayı mali durumlarının kötüye gitmemesi için önemsemeleri gerekli faktörleri ortaya koymaktadır. $\mathrm{Bu}$ bakımdan söz konusu faktörleri dikkate alarak uygun bir politika seyreden bankaların kredi sıkıntısı yaşamayıp performanslarını iyi durumda tutacakları düşünülmektedir.

Finansal Destek: Yazar bu çalışma için finansal destek almamıştır

\section{Kaynaklar}

Ahmad, N. H., \& Ahmad, S. N. (2004). Key factors influencing credit risk of Islamic bank: A Malaysian case. The Journal of Muamalat and Islamic Finance Research, 1(1), 65-80.

Baltagi, B. H. (2005). Econometric Analysis Of Panel Data. England: John Wiley \& Sons .

BDDK. (1.11.2006). Bankalarca Kredilerin ve Diğer Alacakların Niteliklerinin Belirlenmesi ve Bunlar İçin Ayrılacak Karşılıklara İlişkin Usul ve Esaslar Hakkında Yönetmelik. İstanbul: Resmi Gazete.

Claessens, S., Klingebiel, D., \& Laeven, L. (2001). Financial Restructuring in Banking and Corporate-Sector Crises. The National Bureau of Economic Research, Chapter 9650.

Espinoza, R., \& Prasad, A. (2010). Nonperforming Loans İn The GCC Banking System And Their Macroeconomic Effects And Their Macroeconomic Effects. IMF Working Papers, 1-24.

Ferhi, A., \& Chkoundali, R. (2015). Credit Risk and Efficiency: Comparative Study between Islamic and Conventional Banks during the Current Crises. Journal of Behavioral Economics, Finance, Entrepreneurship, Accounting and Transport, 3(1), 47-56.

Ghost, S., \& Das, A. (2007). Determinants of credit risk in indian state-owned banks: An empirical investigation. Economic Issues, 12(2).

Göğebakan, C. M., \& Arda, M. (2004). Kredi Risk Yönetimi Açısından İçsel Derecelendirme Modeli. Active Bankacılık ve Finans Dergisi(34).

Keklik, G. (2011). Bankalarda Kredi Riski Yönetimi Performans Analizi Ve Veri Zarflama Analizi Yöntemi İe Uygulama. Kütahya: Dumlupınar Üniversitesi, Sosyal Bilimler Enstitüsü, İşletme Anabilim Dalı, Yüksek Lisans Tezi.

Klein, N. (2013). Non-Performing Loans In CESEE: Determinants And Impact On Macroeconomic Performance. IMF Working Paper.

Koyuncu, C., \& Saka, B. (2011). Takipteki Kredilerin Özel Sektöre Verilen Krediler ve Yatırımlar Üzerindeki Etkisi. Dumlupınar Üniversitesi, Sosyal Bilimler Dergisi(31), 113-124.

M. Cristea, L. G. (2010). Evaluation of Turkish domestic and foreing banks by using financial ratios. University of Craiova, Faculty of Economy and Business Administration.

Nurul, K., Worthington, A., \& Gupta, R. (2014). Comparative credit risk in Islamic and conventional bank. PacificBasin Finance Journal, 34, 327-353.

Özkan, N., \& Işı1, G. (2016). İslami Bankalarda Kredi Riskini Belirleyen Faktörler: Panel Veri Anazi İle Türkiye'de Katılım Bankacılığı Üzerinde Ampririk Bir Uygulama. Maliye Finans Yazıları Dergisi, 105, 153-176.

Sarı, S. (2004). Ticari bankalarda risk yönetimi ve sermaye yeterliliği. Ankara: Gazi Üniversitesi Sosyal Bilimler Enstitüsü, Yayınlanmış Yüksek Lisans Tezi.

Sözer, İ. A. (2010). Bankalarda Takipteki Krediler: Takibine Yönelik Bir Model Önerisi. İstanbul: Marmara Üniversitesi Bankacılık ve Sigortacılık Enstitüsü, Yüksek Lisans Tezi.

Suresh, N., Kumar, A., \& Gowda, D. M. (2009). Credit risk management in commercial banks. Don Bosco Institute of Bio-Sciences and Management Studies, 2(4), 72-78. 